\title{
Simulation and Experimental Study on Characteristics of Multiorifice Nozzle in Radial Jet Drilling
}

\author{
Tao Zhang, ${ }^{1,2}$ Yumei Li ${ }^{1},{ }^{1}$ Hui Lu, ${ }^{3}$ and Jianing Jiang ${ }^{2}$ \\ ${ }^{1}$ Beijing Key Laboratory of High Dynamic Navigation Technology, Beijing Information Science \& Technology University, \\ Beijing 100101, China \\ ${ }^{2}$ High Dynamic Automation Technology Hejian Co., Ltd., Hejian 062450, China \\ ${ }^{3}$ CNPC Tarim Oilfield Branch, Korla 841001, China \\ Correspondence should be addressed to Yumei Li; liyumei3680238@163.com
}

Received 19 August 2021; Revised 23 November 2021; Accepted 8 December 2021; Published 10 January 2022

Academic Editor: Bing Hou

Copyright (c) 2022 Tao Zhang et al. This is an open access article distributed under the Creative Commons Attribution License, which permits unrestricted use, distribution, and reproduction in any medium, provided the original work is properly cited.

\begin{abstract}
The radial jet drilling (RJD) is a key technology to improve the development efficiency of low-permeability oil and gas resources. In order to seek a reasonable hydraulic engineering parameter combination of hydraulic radial jet drilling, to obtain the optimal hydraulic energy distribution, a jet radial horizontal drilling simulation experiment system of the casing windowing is designed. A sequence of experimental investigations focused on engineering parameters of pump displacement, rotating speed, and frequency of high-pressure plunger pump is performed, and the operability and the feasibility of the experiment are verified. To evaluate the maximum drillable length and the self-propelled force of a jet nozzle, a 3D numerical model based on ANSYS-CFX is developed to evaluate the effects of the inlet flow displacement, the flow rates ratio $K$, and the angle ratio $F$ : $B$ of the forward orifice and backward orifice of the jet nozzle on its maximum drillable length and self-propelled force by sensitivity analysis. Finally, the comparison of numerical simulation results (Ln), mathematical results (Lm), and experiment results (Le) of the maximum drillable length are presented. It is observed that the simulation results are consistent with the experiment results with an average accuracy of $97.07 \%$. Therefore, the proposed numerical model has a good performance in predicting the maximum drillable length of the multiorifice nozzle. The research results can provide theoretical guidance for improving the rock breaking and drilling capability of radial jet drilling technology.
\end{abstract}

\section{Introduction}

Radial jet drilling (RJD) technology was imposed in the 1980s [1]. In the exploration of oil and gas wells, the application of radial jet drilling (RJD) technology can effectively reduce drilling costs for the unconventional oil and gas wells, abandoned renovation wells, and geothermal development wells, especially the exploration or development wells with poor fracturing effects [2-5]. Additionally, the RJD technology has been growing in applications aimed to increase the oil well drainage area and reduce the pore pressure of the reservoir for the low-permeability reservoirs and significantly increased reservoir production [6].
The hydraulic radial jet drilling technology mainly includes two processes: casing windowing and radial jet drilling. One of the cores is the casing windowing technology. Whether the radial jet drilling can be successfully completed depends on the casing windowing. The success of casing windowing directly affects the subsequent channel construction of radial horizontal wells. In the process of the casing windowing, it is necessary to use the blade bit to drill a microwellbore about $25 \mathrm{~mm}$ on the inside of the casing and then to connect the high-pressure hose with a coiled tubing. The high-pressure fluid is sprayed through the jet nozzle to penetrate the rock layer to form a tiny horizontal wellbore with a length of about $100 \mathrm{~m}$ and a diameter of 
about $50 \mathrm{~mm}$, whose radius of curvature is much smaller than that of conventional well $[7,8]$. The radial oil and gas passages break through the near-well reservoir pollution zone and establish multiple diversion channels for the farwell zone, increasing well production. To obtain larger selfpropelled force to pull the hose forward, the jet nozzle design is of great importance when selecting bottom-hole drilling tools. The casing window drilling tool assembly structure is shown in Figure 1.

In recent years, the application of the radial jet drilling (RJD) technology is increasingly investigated to stimulate low performing wells, such as geothermal wells and coalbed methane [9-11]. Chi et al. calculated the maximum drillable length of jet nozzle by theoretical analysis and experiments [12]. Li and Zhang developed a 3D numerical model based on ANSYS-CFX to investigate the self-propelled ability of a multiorifice nozzle, remarkably the effects of the physical parameters of the multiorifice nozzle on its self-propelled ability by sensitivity analysis [13]. Wang et al. conducted the experimental study of the $\mathrm{NGH}$, and focusing on the effects of traverse jetting speed, jetting flow rate on rock breaking was studied [14]. Yang analyzed the effects of the jet velocity, distance, and saturation on the NGH sediment by experiment and simulation [15]. Wang et al. developed an engineering construction chart for solid fluidization well through jet experiments [16]. Liao et al. conducted the rock-breaking experiments of the self-propelled jetting efficiency and developed a numerical model of the selfpropelled force of multiorifice nozzles [17]. For all the above studies, the optimization design of hydraulic parameters of radial horizontal wells and conventional drilling technologies are different in terms of optimization objectives and constraints. The existing hydraulic parameter design methods are not applicable to radial horizontal well technology.

In this paper, a jet radial horizontal drilling simulation experiment system of the casing windowing is designed, and the reasons for not opening window in the experiment are analyzed. To evaluate the maximum drillable length and the self-propelled force of a multiorifice nozzle, a 3D numerical model of the nozzle is established based on ANSYS-CFX. A sequence of simulations are develop to investigate the effects of the inlet flow displacement, the flow rates ratio $K$, and the angle ratio $F: B$ of the forward orifice and backward orifice of the jet nozzle on its maximum drillable length and selfpropelled force by a series of sensitivity analysis. The design method of hydraulic parameters for radial horizontal drilling is proposed, which provides theoretical support for the application of radial horizontal well technology.

\section{The Mathematical Model}

2.1. Calculation of Self-Propelled Force. The recoil force that pushes the nozzle forward is obtained by the kinetic energy theorem of the nozzle outlet section [18].

$$
F \Delta \mathrm{t}=m v_{2}-m v_{1}
$$

where $F$-the force on per unit volume, N;

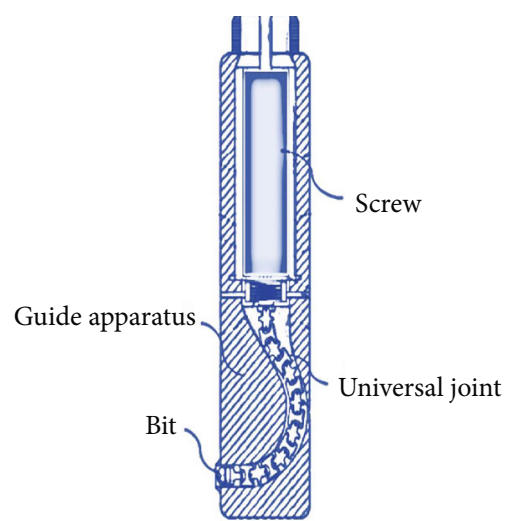

Figure 1: The casing window drilling tool assembly structure.

$\Delta t$-the time on per unit volume of fluid, s;

$m$-the mass of the fluid per unit volume, $\mathrm{kg}$;

$V_{1}$-the average flow velocity in the nozzle outlet section, $\mathrm{m} / \mathrm{s}$;

$V_{2}$-the average flow velocity outside the nozzle outlet section, $\mathrm{m} / \mathrm{s}$.

According to the principle that the acting force is equal to the reaction force, $F$ in the above formula is the jet recoil force $F_{z}$. It is known as $\mathrm{m} / \Delta t=\rho d$, assuming that the flow path of jet nozzle is circular, according to the continuity equation between the outlet sections of jet nozzle, i.e., $A=$ $\pi d^{2} / 4$, it is obtained:

$$
F_{z}=\rho q v_{2}\left[1-\left(\frac{d_{2}}{d_{1}}\right)^{2}\right]
$$

where $\left(d_{2} / d_{1}\right)^{4} \leq 1$

Simplified expression of jet velocity at jet nozzle outlet:

$$
v=44.77 \sqrt{p},
$$

where $P$-the jet pressure, $\mathrm{MPa}$;

$V$-the jet flow rate, $\mathrm{m} / \mathrm{s}$.

Substituting (3) into Equation (2), and finally,

$$
F_{z}=0.745 q \sqrt{p}
$$

where $F_{z}$-the recoil force of water flow, N;

$q$-the jet flow, $\mathrm{L} / \mathrm{min}$.

Substituting the formula into Equation (4) yields another expression:

$$
F_{z}=1.56 d^{2} p
$$

where $d$-the outlet diameter of the nozzle, mm. 
The expression of recoil force is:

$$
F_{f}=n_{1} 1.56 p d_{1}^{2} \cos \theta_{1},
$$

where $n_{1}$-the number of backward orifices;

$\theta_{1}$-the angle of the backward orifices, ${ }^{\circ}$;

$d_{1}$-the diameter of the backward orifices, $\mathrm{mm}$.

The expression of rock breaking force is:

$$
F_{p}=n_{2} 1.56 p d_{2}^{2} \cos \theta_{2}
$$

where $F_{P}$-the breaking rock force, $\mathrm{N}$;

$n_{2}$-the number of forward orifices;

$\theta_{2}$-the angle of the forward orifices, ${ }^{\circ}$;

$d_{2}$-the diameter of the forward orifices, $\mathrm{mm}$.

The self-propelled force of the multiorifice nozzle is expressed as:

$$
F_{t}=F_{z}-F_{p} .
$$

2.2. The Maximum Drillable Length. In the process of hydraulic jet rock breaking, the viscosity of the highpressure hose wall is not considered. Assume that the friction force of the jet nozzle in the horizontal direction is $F_{w}$ , the friction force at the radial borehole wall is $F_{f}$. The resultant force in the horizontal direction of radial jet drilling system is calculated as

$$
F_{\text {pull }}=F_{z}-F_{p}-F_{w}-F_{f},
$$

where

$$
F_{f}=\mu M g+\mu q_{h} g l .
$$

In the above formula, $\mu$ is the sliding friction factor of the wellbore and wall; $l$ is the penetration depth of the high-pressure hose, $\mathrm{m} ; M$ is the mass of the jet nozzle, $\mathrm{kg}$; $q_{h}$ is the mass of the high-pressure hose line, $\mathrm{kg} / \mathrm{m} ; g$ is the gravitational acceleration, $\mathrm{N} / \mathrm{kg}$.

Assuming the jet nozzle is placed horizontally,

$$
\frac{d}{d t}\left[\left(M+l q_{n}\right) v\right]=F_{z}-F_{p}-F_{w}-F_{f},
$$

where $v$ is the drilling speed, $\mathrm{m} / \mathrm{s}$.

For convenience, define a length coordinate:

$$
x=\frac{l+M}{q_{h}}=l+l_{0},
$$

where $x$ is the extension length, $\mathrm{m} ; l_{0}$ is the equivalent length of the jet nozzle, $\mathrm{m}$.
It is assumed that the frictional force $F_{w}$ experienced by the high-pressure hose is a fixed value and can be determined experimentally. Since $F=F_{f}+F_{p}, F$ can be written as:

$$
F=\mu M g+\mu q_{h} g l+\eta\left(l+l_{0}\right) .
$$

According to formula (12),

$$
F=\mu q_{h} g\left(M / q_{h}\right)+\eta\left(l+l_{0}\right)=\left(\mu q_{h} g+\eta\right) x .
$$

In Equation (14), $\eta$ is the coefficient of friction resistance, $\mathrm{N} / \mathrm{m}$.

$$
\mu q_{h} g+\eta
$$

Assume Equation (14) can be simplified to:

$$
F=k x,
$$

where $k$ is the combined friction coefficient, $\mathrm{N} / \mathrm{m}$.

In combination with Equations (11), (12), (14), and (15), we can obtain:

$$
\begin{gathered}
\frac{d}{d t}\left(q_{h} x v\right)=F_{z}-k x-20, \\
\frac{q_{h}}{2} \frac{d}{d t}(x v)^{2}=\left(F_{z}-k x-20\right) x .
\end{gathered}
$$

Initial conditions of a given jet nozzle: $\left.x\right|_{t=0}=l_{0},\left.v\right|_{t=0}=$ $\left.v\right|_{x=l_{0}}=0$.

Integrate Equation (18) to obtain the motion equation:

$$
\frac{q_{h}}{2}(x v)^{2}=\left(F_{z}-20\right)\left(x^{2}-l_{0}^{2}\right)-\frac{k}{3}\left(x^{3}-l_{0}^{3}\right) .
$$

Equation (19) can be written:

$$
\begin{aligned}
\frac{q_{h}}{2}(x v)^{2}= & \left(n \rho Q_{j} v_{j} \cos \theta_{j}-m \rho Q_{i} v_{i} \cos \theta_{i}-\frac{\pi}{4} d_{i}^{2} m p_{\text {out }}-20\right) \\
& \cdot\left(x^{2}-l_{0}^{2}\right)-\frac{k}{3}\left(x^{3}-l_{0}^{3}\right),
\end{aligned}
$$

where $Q_{i}$ is the flow of the $i$ th forward orifice, $L / s, Q_{j}$ is the flow of the $j$ th backward orifice, $\mathrm{L} / \mathrm{s}$; $v_{i}$ is the jet velocity of the $i$ th forward orifice, $\mathrm{m} / \mathrm{s}, v_{j}$ is the jet velocity of the $j$ th backward orifice, $\mathrm{m} / \mathrm{s} ; \theta_{i}$ is the angle of forward orifice, ${ }^{\circ}$; and $\theta_{j}$ is the angle of backward orifice, ${ }^{\circ}$.

Assuming that the value of $k=0.87 \mathrm{~N} / \mathrm{m}$, we get:

$$
\frac{\left(n \rho Q_{j} v_{j} \cos \theta_{j}-m \rho Q_{i} v_{i} \cos \theta_{i}-(\pi / 4) d_{i}^{2} m p_{\text {out }}-20\right)\left(x^{2}-0.25\right)-0.29\left(x^{3}-0.125\right)}{q_{h} x^{2}} .
$$



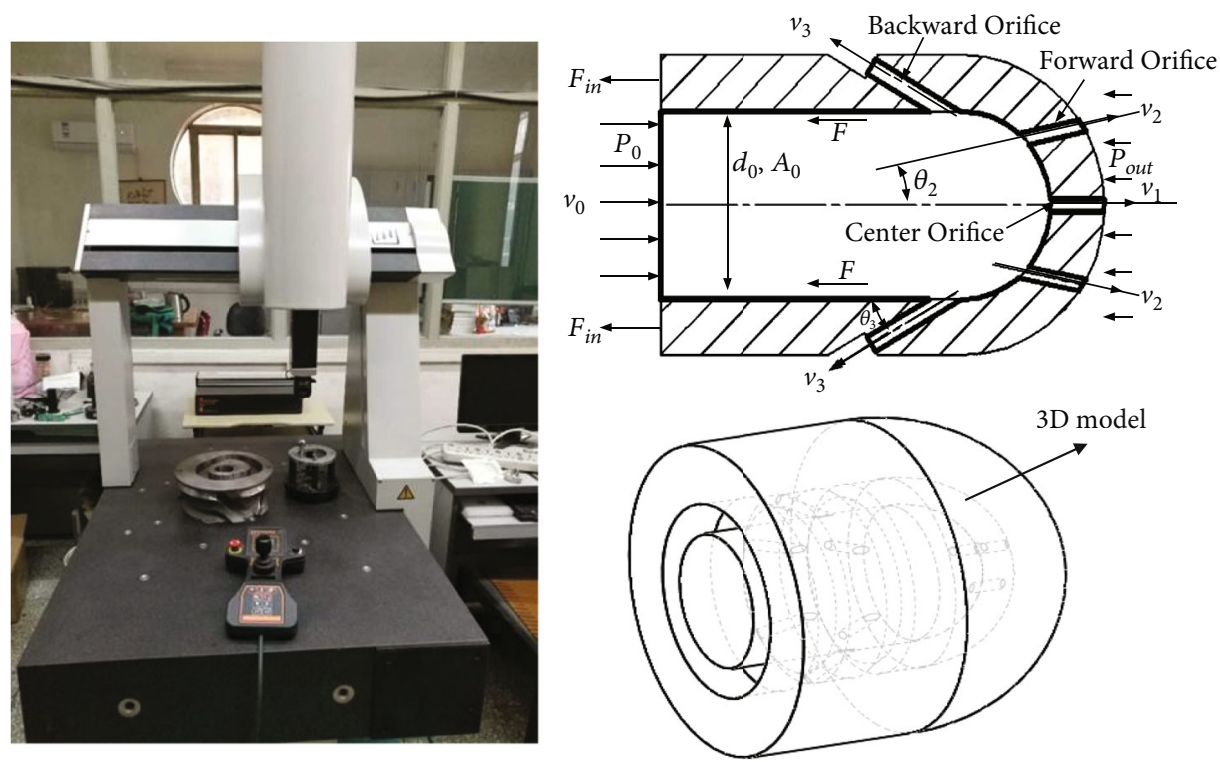

FIGURE 2: The 3D physical geometry model of the nozzle through three-coordinate measuring instrument.

When $v=0$, the maximum drillable length can be expressed as follows:

$$
X=\frac{n \rho Q_{j} v_{j} \cos \theta_{j}-m \rho Q_{i} v_{i} \cos \theta_{i}-(\pi / 4) d_{i}^{2} m p_{\text {out }}-20}{0.29} .
$$

\section{Numerical Simulation}

3.1. Geometry and Boundary. The multiorifice nozzle is the "core" of radial jet drilling (RJD) technology, especially the geometric design of the nozzle will have a greater impact on hydraulic parameters. The measuring instrument (CROMA, Hexagon, Sweden) is used to carry out the mapping design of the multiorifice nozzle. The $3 \mathrm{D}$ physical geometry model of the nozzle is shown in Figure 2 [9]. The diameter of the jet nozzle is $25 \mathrm{~mm}$, the total length is $17.5 \mathrm{~mm}$, the inner diameter is $8.6 \mathrm{~mm}$, the outer diameter is $12.5 \mathrm{~mm}$, the diameter of front orifice is $0.5 \mathrm{~mm}$, the diameter of backward orifice is $0.7 \mathrm{~mm}$; and the inlet ambient pressure $P=30 \mathrm{MPa}$, inlet flow rate $Q_{0}$. The flow field model of the jet nozzle is segmented by $3 \mathrm{D}$ modeling software, and then, the meshing model of multiorifice nozzles was established by ICEM (as shown in Figure 3). The boundary conditions of the inlet, outlet, and wall of the jet nozzle are set in the simulation of flow field characteristics. After setting the boundary conditions, the discrete format and relaxation factor are adjusted.

3.2. Sensitivity Analysis. In this simulation, the inlet flow rate $Q_{0}$ is set to $25 \mathrm{~L} / \mathrm{min}, 35 \mathrm{~L} / \mathrm{min}, 45 \mathrm{~L} / \mathrm{min}$, and $55 \mathrm{~L} / \mathrm{min}$, and multiple simulation models are established. Figure 4 shows the streamline diagram of velocity vector of jet nozzle. The jet velocity distribution diagram of forward orifice under different inlet displacement is shown in Figure 5. The jet velocity distribution diagram of backward orifice under different
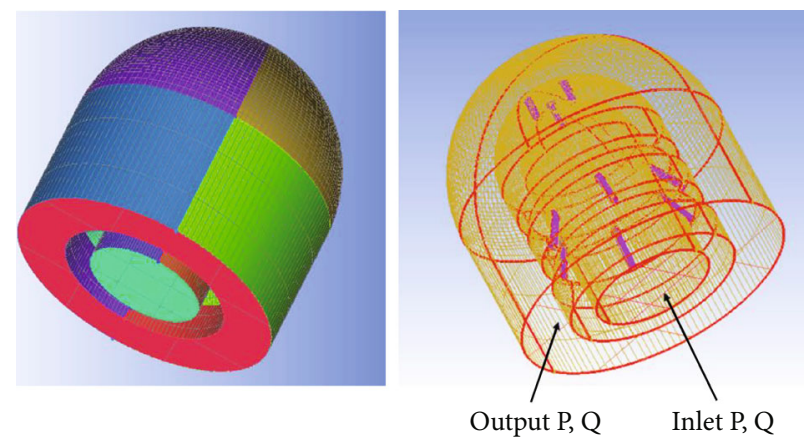

Figure 3: The meshing model of multiorifice nozzle.

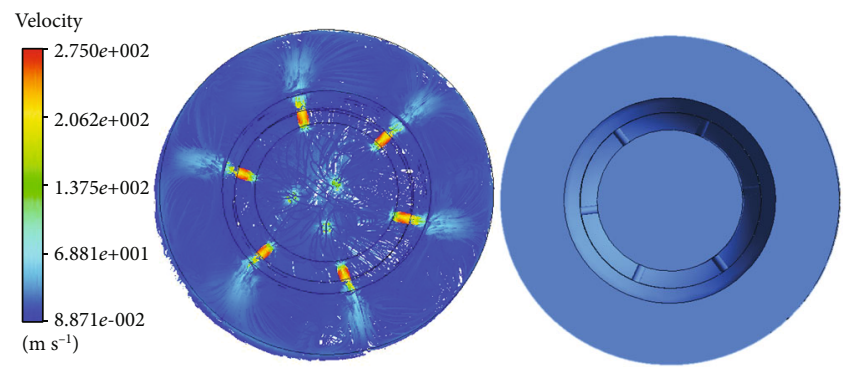

FIgURE 4: The streamline diagram of velocity vector of jet nozzle $(F+B): 3+5$.

inlet flow displacement is shown in Figure 6. In the entire simulation, the maximum jet velocity is distributed near the forward orifices and backward orifices where there is a larger pressure difference.

A series of simulations of the inlet flow displacement on the maximum flow rate of forward orifices and backward orifices of jet nozzle were investigated (as shown in Figure 7). When the inlet displacement $Q=25 \mathrm{~L} / \mathrm{min}$, the velocity of backward orifice is $162.4 \mathrm{~m} / \mathrm{s}$, the velocity of 


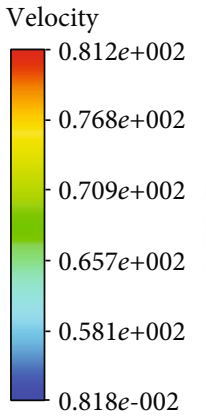

$\left(\mathrm{m} \mathrm{s}^{-1}\right)$

Velocity

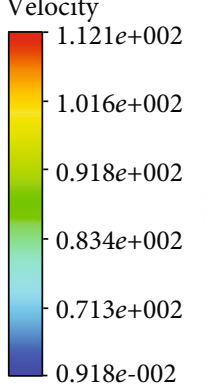

$\left(\mathrm{m} \mathrm{s}^{-1}\right)$

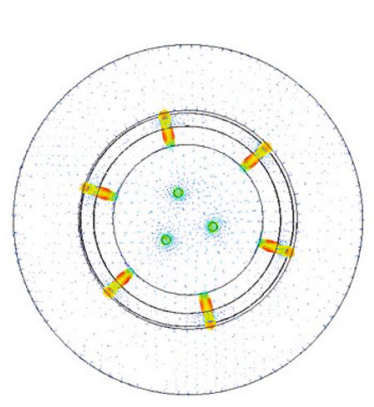

$\mathrm{Q}=25 \mathrm{~L} / \mathrm{min}$

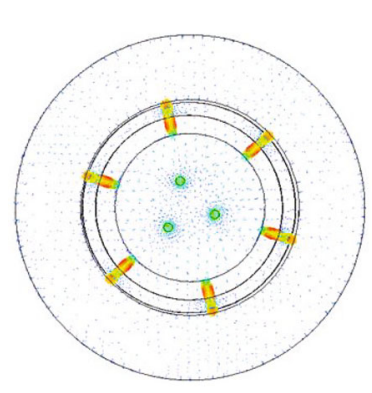

$\mathrm{Q}=45 \mathrm{~L} / \mathrm{min}$

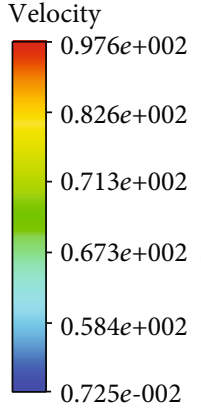

$\left(\mathrm{m} \mathrm{s}^{-1}\right)$

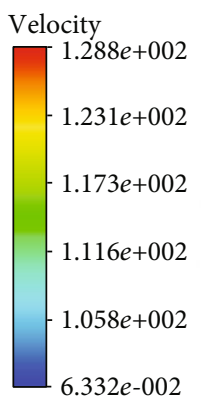

$\left(\mathrm{m} \mathrm{s}^{-1}\right)$
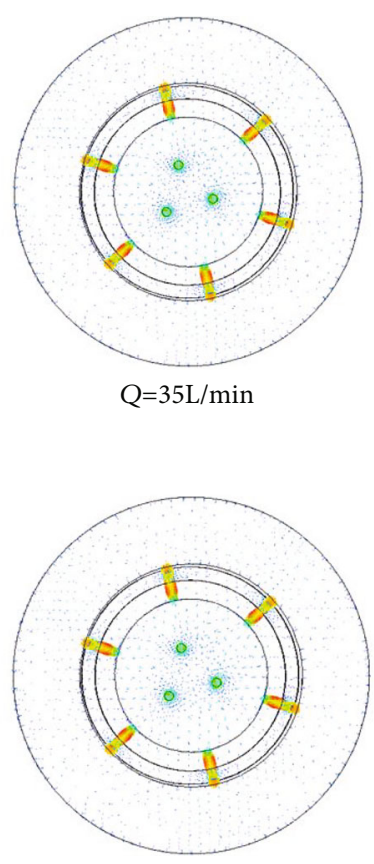

$\mathrm{Q}=55 \mathrm{~L} / \mathrm{min}$

FIgURE 5: The jet velocity distributions of forward orifice under different inlet displacement.

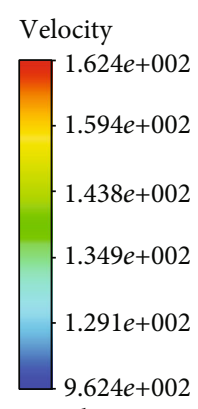

$\left(\mathrm{m} \mathrm{s}^{-1}\right)$

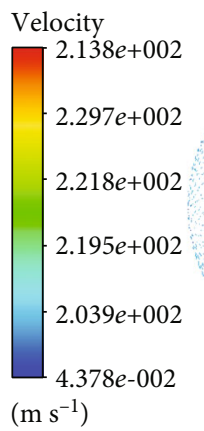

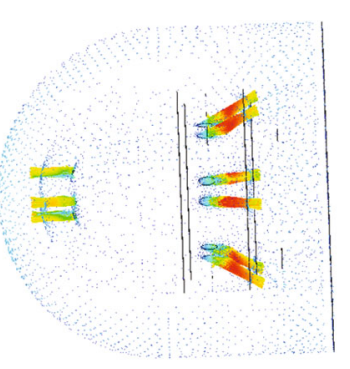

$Q=25 \mathrm{~L} / \mathrm{min}$

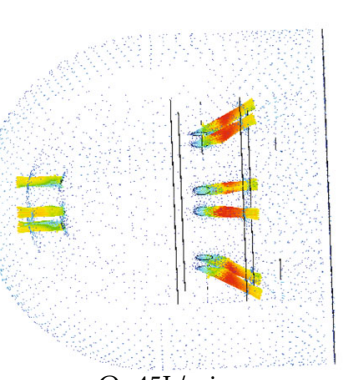

$\mathrm{Q}=45 \mathrm{~L} / \mathrm{min}$
Velocity
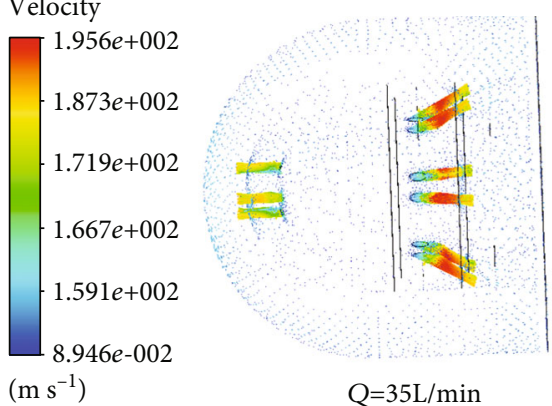

$Q=35 \mathrm{~L} / \mathrm{min}$

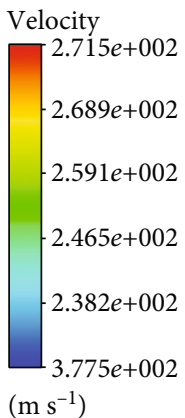

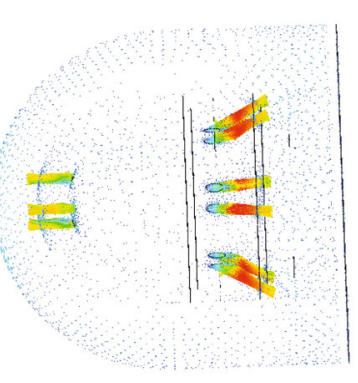

$Q=55 \mathrm{~L} / \mathrm{min}$

FIgURE 6: The jet velocity distributions of backward orifice under different inlet displacement.

forward orifice is $81.2 \mathrm{~m} / \mathrm{s}$, and the maximum flow rate is $199.8 \mathrm{~m} / \mathrm{s}$. It is observed that both the maximum flow rate of forward orifices and backward orifices increase as the inlet displacement increases. The flow rate of the backward orifices is greater than that of the forward orifices when the larger backward driving force can be obtained.
The ratio of the flow rates of the forward orifice to that of the backward orifice of the jet nozzle is defined as [8]:

$$
K=\frac{n_{2} Q_{2}}{n_{1} Q_{1}}=\frac{n_{2} d_{2}^{2}}{n_{1} d_{1}^{2}} .
$$




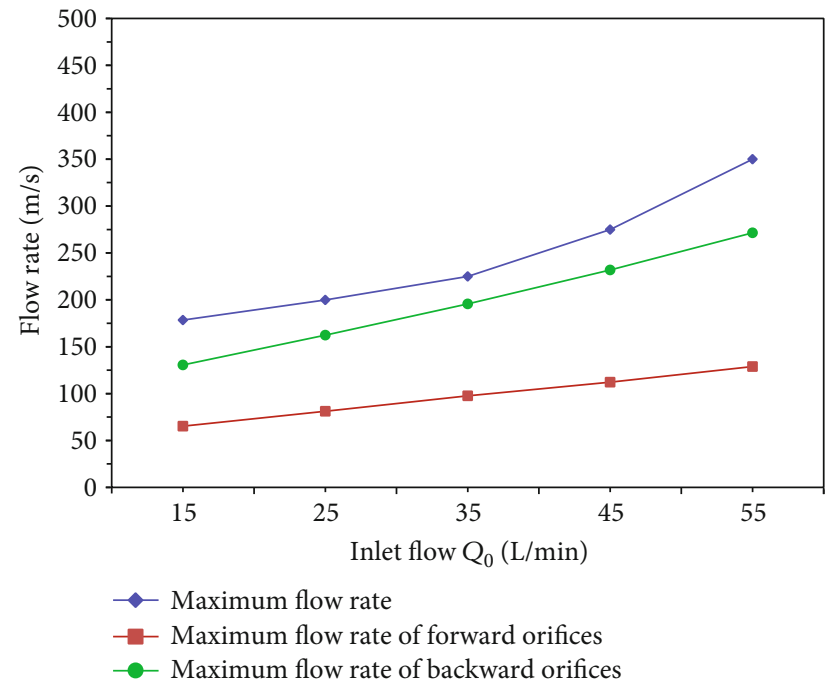

FIGURE 7: Comparison of the maximum speed of the injector under different inlet displacements.

The key parameter will reflect the performance of the jet nozzle. Given the variation of the inlet displacement, the curves of the maximum drillable length versus the ratio $K$ are plotted in Figure 8. As indicated from the comprehensive analysis, the maximum drillable length increases with the ratio $K$ until $K=0.2$, but a decreasing trend of the maximum drillable length is shown when $K>0.2$. As demonstrated from the results, the larger inlet displacement value, the larger the maximum drillable length when $K<0.45$; the larger inlet displacement value, the smaller the maximum drillable length when $K>0.45$. This shows that the ratio $K$ changes within a certain ratio range, and the inlet displacement has a greater impact on the maximum drillable length. The ratio of the flow rates of the forward orifice to that of the backward orifice of the jet nozzle might have an optimal value according to the curve trend when the effect of drilling hole is the best.

The calculated values of the self-propelled force with the inlet displacement are investigated from the simulation results for representative values of the angle ratio of the forward orifice and the backward orifice (as shown in Figure 9). It is obvious that the self-propelled force increases by a larger magnitude when the flow rate $Q<40 \mathrm{~L} / \mathrm{min}$, and the magnitude tends to decrease as the inlet flow rate when $Q$ $>40 \mathrm{~L} / \mathrm{min}$. The simulations show that the self-propelled force is constantly increasing as the ratio $F: B$ decreasing under the same inlet displacement condition. This indicates that the recoil force increases with the increase of the inlet flow displacement, and the increasing trend is greater than that of the rock breaking force. Therefore, it is better to choose the larger inlet flow displacement to increase the recoil force, rock breaking force, and self-propelled force without considering other factors.

\section{Field Experiment Description}

In order to verify the simulation results of multiorifice nozzle, the field application experiment is conducted in well

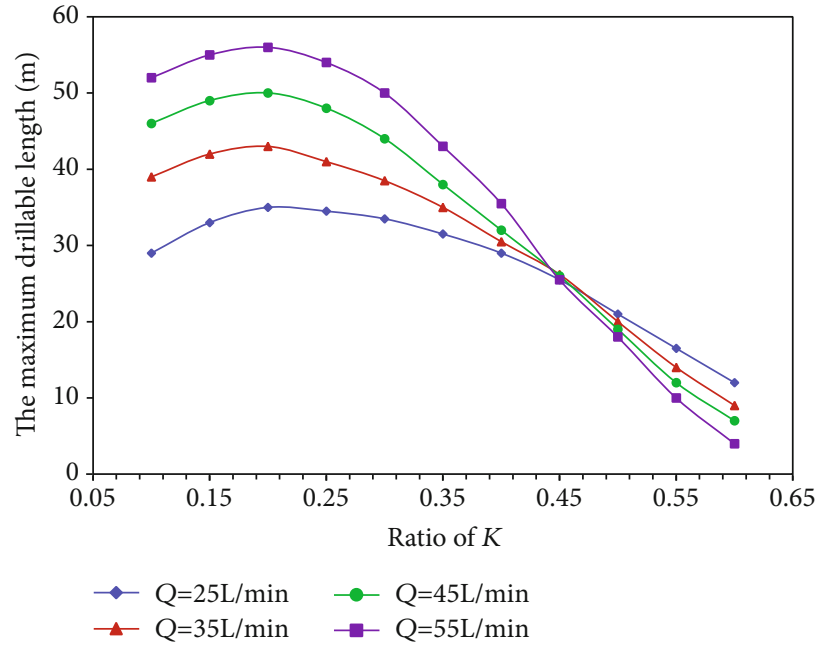

Figure 8: Effect of the ratio $K$ on the maximum drillable length for representative values of $Q$.

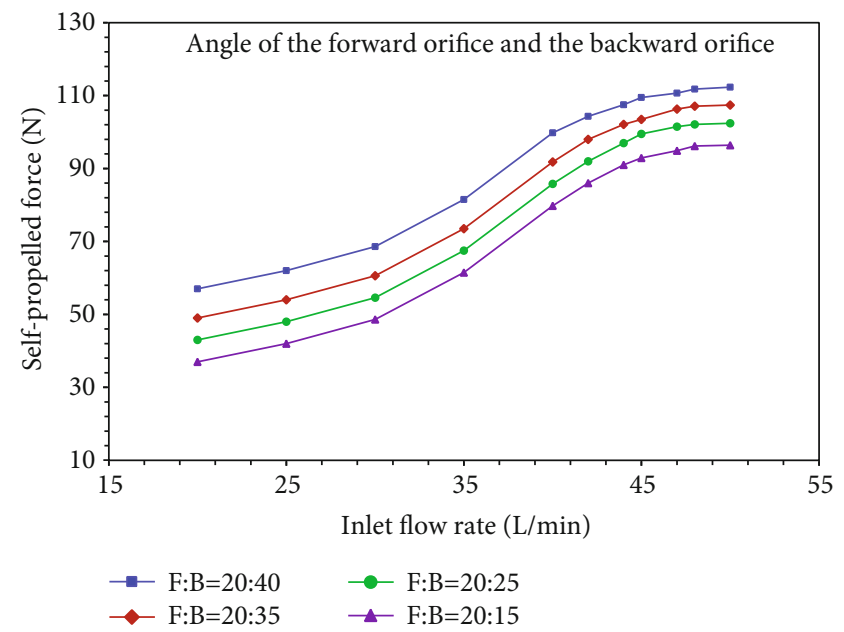

FIGURE 9: Effects of the inlet flow rate on the self-propelled force for representative values of $F: B$.

Nan XX-14, China. The field application apparatuses combination schematic of schematic of an RJD simulation experiment system with high-pressure water is shown in Figure 10.

The vertical depth of radial horizontal well is $2540 \mathrm{~m}$; the inner diameter of the wellbore is $139.7 \mathrm{~mm}$. The inner diameter of the multiorifice nozzle was $20.0 \mathrm{~mm}$, and the outer diameter of the multiorifice nozzle was $12.2 \mathrm{~mm}$. The number of the forward orifice is 3 , and the number of the backward orifice was 6 . The diameter of the forward orifice was $d_{2}=0.50 \mathrm{~mm}$, and the diameter of the backward orifice was $d_{1}=0.70 \mathrm{~mm}$. The angle of the forward orifice was $\theta_{2}$ $=20^{\circ}$, and the angle of the backward orifice was $\theta_{1}=30^{\circ}$; the jetting azimuth is $90^{\circ}$. The working pipe string was the tubing with an outer diameter of $0.06 \mathrm{~mm}$, and the steering gear was put into the predetermined position. The roughness of wellbore wall is $1 \mathrm{~mm}$, and the friction coefficient is 0.3. The jetting fluid is clean water, the density is $988 \mathrm{~kg} /$ $\mathrm{m}^{3}$, and the viscosity is $0.549 \mathrm{mPa} \cdot \mathrm{s}$. The treating pressure 


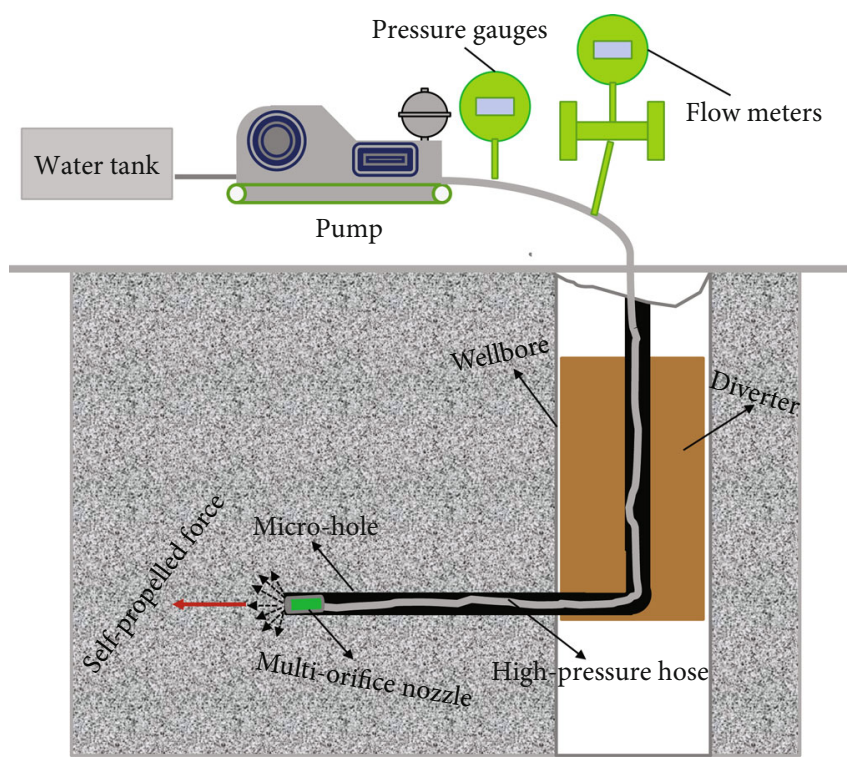

FIGURE 10: Schematic of an RJD system with high-pressure water.

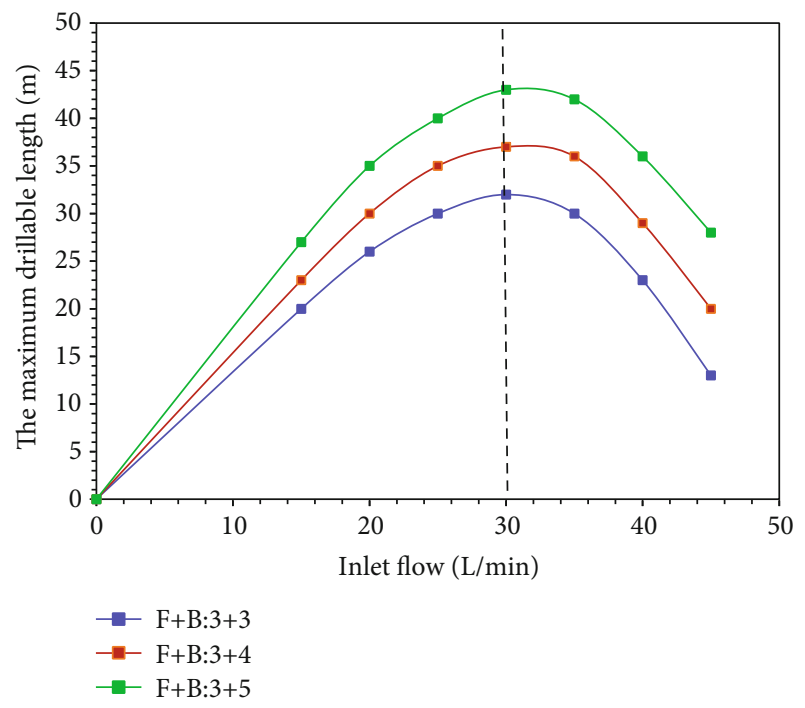

FIGURE 11: Effects of inlet flow on the maximum drillable length at $F+B: 3+6,4+6$, and $5+6$.

is $25 \sim 71 \mathrm{MPa}$, and the slurry proppant concentration is $35 \sim 115 \mathrm{~kg} / \mathrm{m}^{3}$.

In the experiment, it is found that the maximum drillable length of the jet nozzle has an increasing tendency and then decreasing with the increase of inlet flow displacement (as shown in Figure 11). This is because the backward jet flow rate increases as the inlet displacement increases, and the self-propelled force also increases. It is obvious that the self-propelled force is larger when the number of the backward orifices is larger, and then, the maximum drillable length can be obtained. Excessive flow will lead to increased circulating pressure loss of the system and lower pressure drop of jet nozzle, which is not conducive to rock breaking. The inlet flow displacement is controlled around $30 \mathrm{~L} / \mathrm{min}$,

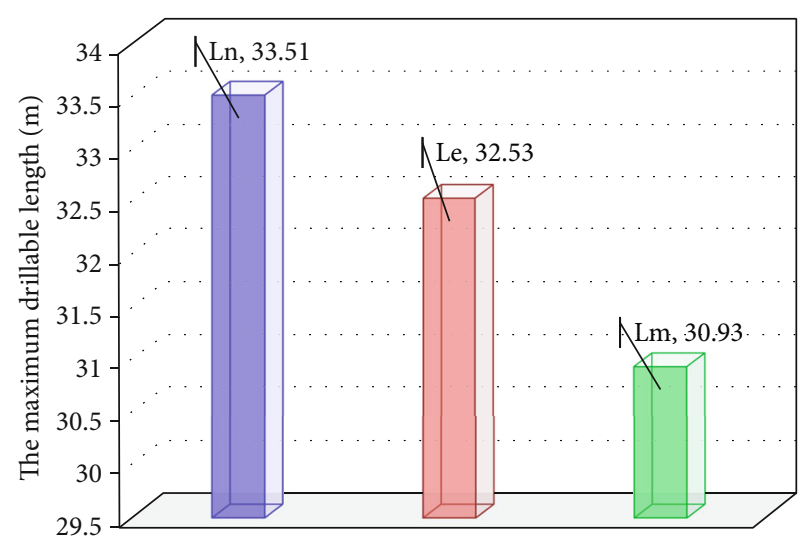

FIgURE 12: Comparison of simulation, calculation, and experiment results of the maximum drillable length.

the maximum drillable length $43.8 \mathrm{~m}$ of the jet nozzle can be obtained for representative values of $F+B: 3+5$. Therefore, it is more reasonable to choose the number of the backward orifices is $B=5$.

Figure 12 shows the comparison of numerical simulation results (Ln), mathematical results (Lm), and experiment results (Le) of the maximum drillable length. It is obvious that the difference between the three results of Ln, Lm, and Le is very small, which proves that the simulation results are consistent with the experiment results with an average accuracy of $97.07 \%$. Therefore, the proposed numerical model has a good performance in predicting the maximum drillable length of the microhole nozzle.

\section{Conclusions}

The research presented in this paper focused on the numerical simulation and experiment of a multiorifice nozzle in radial jet drilling. To evaluate the maximum drillable length and the self-propelled force, a 3D numerical model of multiorifice nozzles based on ANSYS-CFX is developed; the conclusions are summarized as follows:

(1) Multiple simulation models are established to investigate the effects of inlet flow displacement on the flow velocity of the forward orifices and backward orifices of the multiorifice nozzle. The numerical simulation results show that the maximum jet velocity are distributed near the forward orifices and backward orifices where there is a larger pressure difference. Both the maximum flow rate of forward orifices and backward orifices increase as the inlet displacement increases. The flow rate of the backward orifices is greater than that of the forward orifices when the larger backward driving force in rock breaking process can be obtained

(2) As indicated from the comprehensive analysis, the maximum drillable length increases until $K=0.2$, but a decreasing trend of the maximum drillable length is shown when $K>0.2$. When $K<0.45$, the 
larger inlet displacement value, the larger the maximum drillable length; when $K>0.45$, the result is the opposite. This shows that the ratio of $K$ changes within a certain ratio range, and the inlet displacement has a greater impact on the maximum drillable length

(3) The simulations show that the self-propelled force is constantly increasing as the ratio $F: B$ decreasing under the same inlet displacement condition. The self-propelled force increases by a larger magnitude when the flow rate $Q<40 \mathrm{~L} / \mathrm{min}$, and the magnitude tends to decrease as the inlet flow rate when $Q>40$ $\mathrm{L} / \mathrm{min}$

(4) The comparison of numerical simulation results (Ln), mathematical results (Lm), and experiment results (Le) of the maximum drillable length are presented. The difference between Ln, Lm, and Le is very small, which proves that the simulation results are consistent with the experiment results with an average accuracy of $97.07 \%$. Therefore, the proposed numerical model has a good performance in predicting the maximum drillable length of the multiorifice nozzles

\section{Data Availability}

All data generated or used during the study appearing in the submitted article are available from the corresponding author upon request.

\section{Conflicts of Interest}

The authors declare that there is no conflict of interest regarding the publication of this paper.

\section{Acknowledgments}

The authors gratefully acknowledge the financial support of the National Natural Science Foundation of China, grant/ award numbers: 52104001 and 41802197; Beijing Municipal Education Commission "Science and Technology General Project", grant/award number: KM202111232004; Key Research Cultivation Program of Beijing Information Science \& Technology University, grant/award number: 2121YJPY220; and the Strategic Cooperation Technology Projects of CNPC and CUPB grant/award number: ZLZX2020-03.

\section{References}

[1] W. Dickinson and R. W. Dickinson, "Horizontal radial drilling system," in Presented at the SPE California Regional Meeting, pp. 27-29, Bakersfield, California, 1985.

[2] G. Shu, H. L. Zhang, Q. Cao et al., "How to decide the well and the rock layer to be stimulated by radial hydraulic jet drilling," Drilling and Production Technology, vol. 40, no. 3, pp. 46-49, 2017.

[3] W. J. Cai, Z. H. Wu, Y. F. Nie, T. Han, J. J. Zhang, and P. Zhou, "Key technology and experimental study on water jet radial drilling," Drilling and Production Technology, vol. 39, no. 4, pp. 1-4, 2016.

[4] G. S. Li, Z. W. Huang, and J. B. Li, "Study of the key techniques in radial jet drilling," Petroleum Drilling Technique, vol. 45, no. 2, pp. 1-9, 2017.

[5] D. Yang, Q. Y. Gao, Y. J. Zhu, X. Q. Zhang, B. D. Zheng, and $\mathrm{X}$. C. Wu, "Research and application of radial hydraulic jet drilling technology in oil and gas well," Gas and Oil Well Testing, vol. 26, no. 1, pp. 67-69, 2017.

[6] P. Buset, M. Riiber, and E. Arne, "Jet drilling tool: cost-effective lateral drilling technology for enhanced oil recovery," in Paper SPE 68504 Presented at the SPE/ICoTA Coiled Tubing Roundtable, Houston, Texas, USA, 2001.

[7] G. Bi, G. S. Li, Z. Qu et al., "Rock breaking efficiency of the selfpropelled swirling jet bit," Acta Petrolei Sinica, vol. 37, no. 5, pp. 680-687, 2016.

[8] U. Stanislay, B. Alexander, and T. Eygeny, "First results of cyclic steam stimulations of vertical wells with radial horizontal bores in heavy oil carbonates," in Paper SPE 115125 Presented at the 2008 Russian Oil and Gas Technical Conference and Exhibition, pp. 28-30, Moscow, Russia, 2008.

[9] J. Li, G. Li, Z. Huang, X. Song, R. Yang, and K. Peng, "The selfpropelled force model of a multi-orifice nozzle for radial jet drilling," Journal of Natural Gas Science and Engineering, vol. 24, pp. 441-448, 2015.

[10] L. Jingbin, H. Zhongwei, Z. Guangqing, L. Xin, and L. Huan, "Rock breaking characteristics of the self-rotating multiorifices nozzle applied to coalbed methane radial jet drilling," International Journal of Rock Mechanics and Mining Sciences, vol. 136, article 104483, 2020.

[11] X. Song, Z. Lyu, L. Cui, G. Li, G. Ji, and Z. Pang, "Comparison of numerical analysis on the downhole flow field for multiorifice hydrothermal jet drilling technology for geothermal wells," Geothermics, vol. 70, pp. 314-323, 2017.

[12] H. Chi, G. Li, Z. Huang, S. Tian, and X. Song, "Maximum drillable length of the radial horizontal micro-hole drilled with multiple high-pressure water jets," Journal of Natural Gas Science and Engineering, vol. 26, pp. 1042-1049, 2015.

[13] Y. Li and T. Zhang, "Investigation of the factors affecting the self-propelled force in a multi-orifice nozzle using a novel simulation method," Energy Science \& Engineering, vol. 8, pp. 112, 2020.

[14] L. Wang, G. Wang, L. Mao, Q. Fu, and L. Zhong, "Experimental research on the breaking effect of natural gas hydrate sediment for water jet and engineering applications," Journal of Petroleum Science and Engineering, vol. 184, article 106553, 2020.

[15] L. Yang, Study on the Breaking Process of Marine Hydrate Subjected to High Pressure Water Jet and the Production Increase of Marine Hydrate Reservoirs Reconstruction, Jilin University, Changchun, 2018.

[16] G. Wang, L. Zhong, S. Zhou et al., "Jet breaking tools for natural gas hydrate exploitation and their support technologies," Natural Gas Industry B, vol. 5, no. 4, pp. 312-318, 2018.

[17] H. Liao, J. Niu, Y. Cheng, Z. Huang, and D. Ma, "Experiment study on water jet breaking rock by multi-orifice nozzle," Journal of China Coal Society, vol. 36, no. 11, pp. 1858-1862, 2011.

[18] P. Wu, "The parameters optimization that based on the finite element simulation of hydraulic injection radial drilling technology," Advanced Materials Research, vol. 616-618, pp. 944947, 2012. 